\title{
THE ALGORITHM OF SUPPLEMENTARY ARGUMENTS INCLUSION FOR INTERVAL MODELS STRUCTURAL IDENTIFICATION OF THE STATIC SYSTEMS
}

\author{
Mykola Dyvak, Volodymyr Manzhula \\ Department of Computer Sciences \\ Institute of Computer Information Technologies \\ Ternopil Academy of National Economy \\ 3 Peremoga Square, Ternopil 46004, Ukraine \\ e-mail: mdy@tanet.edu.te.u
}

The tasks of "input-output" models construction in the static systems are mainly decided on the basis of experimental data in three stages: design of experiment, which results will be a priori provided by the set of models' properties; identification of model's structure; identification of its parameters. Identification of model's structure, which is not subject to complete formalization there is the most difficult stage.

For the solve of structural identification task it is necessary to define errors nature in experimental data. The method of their description determines general approach which is the base for the methods model's structure synthesis. Nowadays for construction of structural identification methods are used two approaches: stochastic and interval (for bounded errors of data).

Within the boundaries of stochastic approach for the synthesis of satisfactory "input-output" models' structure of the static systems often the methods of consequent parameters inclusion or exception are used, which are built on statistical criteria of hypotheses verifications about meaning of model parameters. The methods of exhaustive search of all possible structures are used seldom. More effective, in relation to indicated, there are different modifications of method of group consideration arguments (MGCA), which are suitable in the conditions of small data retrieval. Basic principles of indicated methods for estimation of the built model "quality", in these methods statistical criteria are used also. It should note high calculable complication of all MGCA algorithms extraordinarily.

Subject to the condition of errors limited on amplitude usage of the indicated methods with the statistical criteria of quality control of structural identification of "input-output" models of the static systems becomes impossible. At these conditions the interval approach is more suitable. Within the limits of interval approach for the tasks of structural identification usage of similar methods models of successive increase or withdrawal of elements of the initial set structure are used. However the criteria of structure optimum do not require statistical researches of experimental data errors.

At the same time analysis of methods of structural identification models "input-output" of the static systems, built on the basis of interval approach showed that all of them did not give the synonymous solution. Therefore actual there is the problem of providing of synonymous solution of structural models identification task by the methods of interval data analysis. The on occasion given problem can be decided by addition or modification of the system of existent criteria which properties of model structure, which are determined by models properties, that is the researching subject of the given article.

Let's assume that the model of static system generally is of such kind function:

$$
y_{o}=y(\vec{x})
$$

where $y_{o}-$ unknown true value of the system output variable; $\vec{x} \in R^{n}$ - vector of input variables; $n$ the initial fixed quantity of input variables, which is necessary to estimate on the basis of experiment results.

For identification of dependence $y(\vec{x})$ the known results of experiment, presented as a matrix $X$ of values of input variables and proper interval of output variable $y$ :

$$
X=\left\{x_{i 1} \ldots x_{i n}, i=1, . ., N\right\} ;[\vec{Y}]=\left\{\left[y_{i}^{-} ; y_{i}^{+}\right], i=1, \ldots, N\right\}
$$


and it is known here, that in every $i$ supervision the true value of output $y_{o i}$ belongs to the interval $\left[y_{i}^{-}, y_{i}^{+}\right]$, that is $y_{i}^{-} \leq y_{o i} \leq y_{i}^{+}$.

In a matrix $X$ there is the possible same columns that will mean the reiteration of supervisions at the same input variables. Thus we will get the selection of interval estimations of output variable $d_{j}=\left\lfloor y_{j}-\Delta ; y_{j}+\Delta\right\rfloor \mathrm{j}=1, \ldots, \mathrm{N}$. We will assume that this selection is accidental, but also includes the not random limited error term of supervisions. That is we consider the model of the mixed interval error $\Delta=\Delta_{1}+\Delta_{2}$, when the results of supervisions after an output variable are set in such kind

$$
y_{i}=y_{0 i}+e_{1 i}+e_{2 i}
$$

where $e_{1 i}$ - the not random limited error with the known range of possible values $-\Delta_{1 i} \leq e_{1 i} \leq \Delta_{1 i} ; e_{2 i}$ random error, that has the symmetric (in the general case unknown) distributing on the known interval $\left[-\Delta_{2 i} ; \Delta_{2 i}\right]$.

The resulted task of identification of dependence $y(\vec{x})$, is enough difficult and in the general case for the receive of its solution it is necessary to consider additional assumption on the class of functions $y(\vec{x})$. We will search dependence $y(\vec{x})$ in class of the linear-parametric equations in such general kind:

$$
y(\vec{x})=\vec{\varphi}^{T}(\vec{x}) \cdot \vec{b},
$$

where $\vec{b}$ - vector of unknown parameters estimations; $\vec{\varphi}^{T}(\vec{x})$ - vector of unknown base functions, but known class (for example, polynomial functions). The dimension $m$ of these vectors at the beginning of identification procedure is known.

Taking into described above and equations (1)-(4), the task of structural identification of "input-output" model on the basis of interval data (2) is erected to finding of such dependences (4), which provide the solutions set of the interval system to the linear (in relation to parameters) of algebraic equations (ISLAE)

$$
y_{i}^{-} \leq b_{1} \varphi_{1}\left(\vec{x}_{i}\right)+\ldots+b_{m} \varphi_{m}\left(\vec{x}_{i}\right) \leq y_{i}^{+}, i=1, \ldots, N
$$

We should note that the solution set $\Omega$ of estimations parameter of model (4) which in space of parameters is the polyhedron and is the solution ISLAE (5). Every estimation from the solution set $\Omega$ at the fixing structure model allows us to get one interval model, that belongs to the functional corridor

$$
[y(x)]=\left[y^{-}(x) ; y^{+}(x)\right],
$$

where

$$
y^{-}(\vec{x})=\min _{\vec{b} \in \Omega}\left(\vec{\varphi}^{T}(\vec{x}) \cdot \vec{b}\right)
$$

and

$y^{+}(\vec{x})=\max _{\vec{b} \in \Omega}\left(\vec{\varphi}^{T}(\vec{x}) \cdot \vec{b}\right)-$ low and upper bounds of functional corridor.

Obviously, that the compatibility terms of the system (5) can be provided by complication of initial model structure $y(\vec{x})=\vec{\varphi}^{T}(\vec{x}) \cdot \vec{b} \quad$ (increase of parameters quantity, inputs, and for polynomial model- polynomial degree).

At solving of structural identification tasks, the choice of optimum structure criteria is an important question. Usually these criteria are the criteria of model's prediction accuracy and complication (simplicity).

General characteristic of interval model's prediction accuracy on the experiment area are the values of average and maximal prediction errors.

In depending on the features of the model used, in the them of "simplicity" of model structure can be put a different sense. In this case implementation of one of such requirements is the most typical situations: minimization is the degrees of polynomial $p \rightarrow \min$; minimization of input model variables quantity of $n \rightarrow$ min; minimization of model parameters quantity $m \rightarrow \min$, on condition of compatibility providing of the interval system of the linear algebraic equation (5).

Consequently, for the tasks of optimum structure synthesis, depending on setting and features of interval model of the static system, it is necessary to use one or a few pairs of criteria: minimizations of the degrees of polynomial model and prediction error; minimizations of input variables quantity of model and prediction error; minimizations of polynomial model parameters quantity and prediction error. Thus providing of the system compatibility is necessary (5).

In the case of the step by step estimation of interval models structures according to chosen criteria, obviously, criteria, that minimize complication of structure, will have a priority. The criterion of prediction error minimum of interval model requires considerable calculable charges and on the first stage related to the evaluation of a plenty applicants, his application is inadvisable. For close estimation of prediction error of interval model in the tasks of structural identification the sizes of localization of the parameters set $\Omega$ are used. In this case interval localization of the parameters set $\Omega$ is most suitable, that is by the described $m$ - dimension rectangular parallelepiped $\Pi^{+}$. In the multidimensional case a rectangular parallelepiped $\Pi^{+}$can be described lower and upper bounds of separate parameters $b_{k}$, that is by an interval vector $[\vec{b}]$ with elements $\left[b_{k}{ }^{-} ; b_{k}{ }^{+}\right]$

$$
\Pi^{+}=\left\{\vec{b} \mid b_{k}^{-} \leq b_{k} \leq b_{k}^{+}, k=1, \ldots, m\right\},
$$

where $b_{k}^{-}=\min _{\vec{b} \in \Omega} b_{k}, b_{k}^{+}=\max _{\vec{b} \in \Omega} b_{k}$. 
In this case the volume of localization parallelepiped can be close estimation of interval models prediction accuracy

$$
V\left(\Pi^{+}\right)=\prod_{k=1}^{m}\left(b_{k}^{+}-b_{k}^{-}\right) .
$$

Consequently in the general case the task of structural identification of interval "input-output" models of static system subject to the condition optimization of complication and prediction accuracy will be such type:

$$
n \rightarrow \min , m \rightarrow \min , V\left(\Pi^{+}\right) \rightarrow \min ,
$$

on condition of the system compatibility (5).

A presence in the mixed model of error $e_{1 i}$ results in a volume, that the repeated experiments allow to decrease the accidental constituent of error only $e_{2 i}$. At the experiments reiteration, the true value $y_{0 i}$ belongs to the crossing of accidental selective intervals

$$
d_{i j}=\left[y_{i j}-\Delta_{i} ; y_{i j}+\Delta_{i}\right] \mathrm{j}=1, \ldots, N_{i}, \sum_{i=1} N_{i}=N \text {. }
$$

If the indicated condition is not executed, that is $\bigcap_{j=1}^{N_{i}} d_{i j}=\varnothing$, it is necessary to increase value $\Delta_{i}$ (width of intervals $d_{i j}=\left\lfloor y_{i j}-\Delta_{i} ; y_{i j}+\Delta_{i}\right\rfloor$ ), for providing of compatibility of the system (5).

Lets $\bigcap_{j=1}^{N_{i}} d_{i j} \neq \varnothing$. We will note the resulting width (to the crossing) of interval $S_{N_{i}}$ in the $i$ point of supervisions after $\Delta_{N_{i}}=s_{N_{i}}^{+}-s_{N_{i}}^{-}$.

At application of the mixed interval error such question is suitable: what the accidental constituent of error which can be compensated by the repeated supervisions at the same values of the fixed input variables is due to? Obviously, that the accidental additive component $e_{2 i}$ of total error in equation (3) is mainly conditioned by action of the untaken into account and uncontrolled factors. The analysis of this components at the repeated supervisions allows to assert that the growth of its amplitude, related to no the consideration of important factors of influence on a "output", will result in one of two cases: definite compensation (narrowing) of width $\Delta_{N_{i}}$ of resulting interval $S_{N_{i}}$ - on condition of the enough large initial set value of interval error $\Delta_{i}$, or to the necessity of expansion of initial interval $d_{i j}$ (increase $\left.\Delta_{i}\right),-$ if $\bigcap_{j=1}^{N_{i}} d_{i j}=\varnothing$. In any case resulting intervals $S_{N_{i}}$ will be wide enough, that will result in low prediction accuracy of interval models.
Laid out allow the higher reasoning to walk up to the task of structural identification from other point of view, namely criterion of complication, which sets the optimum quantity of input variables to substitute by the criterion of "additional arguments-inputs" $n \rightarrow \min$, which will set the average area of experiment correlation between the width of resulting and initial intervals for output variable

$$
\frac{1}{N} \sum_{i=1}^{N} \frac{\Delta_{N i}}{\Delta_{i}} \stackrel{n, \Delta_{i}}{\longrightarrow} \max
$$

for terms $\bigcap_{j=1}^{N_{i}} d_{i j} \neq \varnothing \quad \forall i$.

The maximal value of expression $\frac{1}{N} \sum_{i=1}^{N} \frac{\Delta_{N i}}{\Delta_{i}}$ is 1, when the initial width of interval remains unchanging at the repeated supervisions. In this case there are absent factors which bring in an random component of error, that allows decreasing the width of interval $\left[y_{i}^{-} ; y_{i}^{+}\right]$by the withdrawal of random component $e_{2 i}$ and the same increase prediction accuracy of the system model. By replacement of criterion $n \rightarrow \min$ in the task of structural identification (7), (5) on a criterion (8) we come to it such kind:

$$
\frac{1}{N} \sum_{i=1}^{N} \frac{\Delta_{N i}}{\Delta_{i}} \stackrel{n, \Delta_{i}}{\longrightarrow} \max
$$

on condition of the system compatibility (5).

Algorithms of multicriterion task solving (9), subject to the condition (5), as well as practical most tasks of structural identification, behave to the evolutionary algorithms. The methods of successive inclusion or elements exception of model structure are a basis for their construction.

In paper there is considered possible algorithms of structural identification of interval models of the system on the basis of criteria (9) with the accounting limitation (5), built on the method of successive elements inclusion.

Possibility of receipt of same solution of tasks of structural identification is shown for different initial model structures. However there is dependence of the given solutions on the initial output variables intervals, which it is impossible to define only at presence of sensor errors. At set wide intervals of output variable we get interval models with unsatisfactory predicted properties. For reduction of sensitiveness of the considered algorithm of structural identification to the initial set interval errors the offered his modification in direction of the adaptive adjusting of possible part of random error term in relation to the error of measuring, by application of iterative adaptive procedure. 


\title{
УРАХУВАННЯ ДОДАТКОВИХ АРГУМЕНТІВ В ЗАДАЧАХ СТРУКТУРНОЇ ІДЕНТИФІКАЦІЇ ІНТЕРВАЛЬНИХ МОДЕЛЕЙ СТАТИЧНИХ СИСТЕМ
}

\author{
Микола Дивак, Володимир Манжула \\ Тернопільська академія народного господарства \\ Інститут комп’ютерних інформаційних технологій, \\ Кафедра комп'ютерних наук \\ Площа Перемоги 3, м. Тернопіль 46004, Україна \\ e-mail: mdy@tanet.edu.te.ua
}

\begin{abstract}
Резюме: Розглянуто задачу структурної ідентифікації інтервальних моделей статичних систем. Показано можливість отримання однозначного розв'язку задачі структурної ідентифікації для різних початково заданих структур моделей на основі запропонованого алгоритму послідовного ускладнення структур. Запропоновано адаптивну ітераційну процедуру, яка зменшує залежність результату структурної ідентифікації від величини інтервальних похибок даних.
\end{abstract}

Ключові слова: структурна ідентифікація, інтервальні моделі, інтервальний аналіз даних

\section{ВСТУП}

Задачі побудови моделей "вхід-вихід" статичних систем на основі експериментальних даних переважно розв'язують у три етапи: планування оптимального експерименту, результати якого апріорі забезпечать задані властивості моделей; ідентифікація структури моделі; ідентифікація ії параметрів. При цьому найбільш складним етапом, який не підлягає повній формалізації $є$ ідентифікація структури моделі $[1,2]$.

Для розв'язання задачі структурної ідентифікації необхідно визначити природу похибок в експериментальних даних. Спосіб їх опису визначає загальний підхід, на якому базуються методи синтезу структури моделі. На сьогоднішній день для побудови методів структурної ідентифікації використовуються два підходи: стохастичний $[2,5,6]$ та інтервальний (теоретико-множинний) $[1,7]$.

В межах стохастичного підходу для синтезу задовільної структури моделей „вхід-вихід” статичних систем найчастіше використовуються методи послідовного включення чи виключення параметрів, які побудовані на статистичних критеріях перевірки гіпотез про значущість параметрів моделі. Рідше використовуються методи повного перебору усіх можливих структур. Більш ефективними, по відношенню до вказаних, є різні модифікації методу групового урахування аргументів (МГУА), які $\epsilon$ придатними в умовах малої вибірки даних $[5,6]$. Основні принципи, на яких побудовані вказані методи, та приклади їх багаточисленного застосування наведені в працях Івахненка А. Г., Степашка В.С. Однак, для оцінки "якості" побудованої моделі, в цих методах також використовуються статистичні критерії. Слід також відмітити надзвичайно високу обчислювальну складність усіх алгоритмів МГУА.

За умов обмежених по амплітуді похибок 3 невідомими законами розподілу застосування вказаних методів зі статистичними критеріями перевірки якості структурної ідентифікації моделей "вхід-вихід" статичних систем стає неможливим. За цих умов більш придатним $€$ інтервальний підхід. В межах інтервального підходу для розв'язування задач структурної ідентифікації моделей використовуються подібні методи послідовного нарощування чи вилучення елементів початково заданої структури. Однак критерії оптимальності структури не вимагають статистичних досліджень похибок експериментальних даних $[1,7]$. 
В той же час аналіз методів структурної ідентифікації моделей “вхід-вихід” статичних систем, побудованих на основі інтервального підходу показав, що усі вони не дають однозначного розв'язку. Тому актуальною $є$ проблема забезпечення однозначного розв'язку задач структурної ідентифікації моделей методами аналізу інтервальних даних. В окремих випадках дану проблему можна розв'язати шляхом доповнення чи модифікації системи існуючих критеріїв, якими визначаються властивості структури моделі [7], що $є$ предметом досліджень у даній праці.

\section{ПОСТАНОВКА ЗАДАЧІ}

Розглянемо задачу структурної ідентифікації статичної системи у випадку інтервальних даних.

Модель статичної системи описується деякою функцією

$$
y_{o}=y(\vec{x})
$$

де $y_{o}-$ істинне невідоме значення виходу системи; $\vec{x} \in R^{n}$ - вектор вхідних змінних; $n-$ задає початкову фіксовану кількість вхідних змінних, яку необхідно встановити на основі результатів експерименту.

Для ідентифікації залежності $y(\vec{x})$ відомі результати експерименту, представлені у вигляді матриці $X$ значень вхідних змінних $\mathrm{i}$ відповідних інтервальних значень вихідної змінної $y$ :

$$
X=\left(\begin{array}{l}
x_{11} \ldots x_{1 n} \\
\vdots \\
x_{i 1} \ldots x_{i n} \\
\vdots \\
x_{N 1} \ldots x_{N n}
\end{array}\right) ;[\vec{Y}]=\left(\begin{array}{l}
{\left[y_{1}^{-} ; y_{1}^{+}\right]} \\
\vdots \\
{\left[y_{i}^{-} ; y_{i}^{+}\right]} \\
\vdots \\
{\left[y_{N}^{-} ; y_{N}^{+}\right]}
\end{array}\right)
$$

і при цьому відомо, що в довільному $i$-у спостереженні істинне значення виходу $y_{o i}$ належить інтервалу $\left[y_{i}^{-}, y_{i}^{+}\right]$, тобто

$$
y_{i}^{-} \leq y_{o i} \leq y_{i}^{+}
$$

У матриці $X$ можливе повторення стрічок, що означатиме повторення спостережень при одних і тих же вхідних змінних. При цьому отримуватимемо вибірку інтервальних оцінок вихідної змінної

$$
d_{j}=\left\lfloor y_{j}-\Delta ; y_{j}+\Delta\right\rfloor \mathrm{j}=1, \ldots, \mathrm{N} .
$$

Припустимо, що ця вибірка є випадковою, але також включає обмежену не випадкову похибку спостережень. Тобто розглядаємо модель змішаної інтервальної похибки $\Delta=\Delta_{1}+\Delta_{2}$, коли результати спостережень за вихідною змінною задаються у такому вигляді [8]

$$
y_{i}=y_{0 i}+e_{1 i}+e_{2 i},
$$

де $e_{1 i}$ - невипадкова обмежена похибка 3 відомим діапазоном можливих значень $-\Delta_{1 i} \leq e_{1 i} \leq \Delta_{1 i} ; e_{2 i}$ - випадкова похибка, що має симетричний (у загальному випадку невідомий) розподіл на відомому інтервалі $\left[-\Delta_{2 i} ; \Delta_{2 i}\right]$.

Наведена задача ідентифікації залежності $y(\vec{x}), \epsilon$ достатньо складною і в загальному випадку для отримання ii розв'язку необхідно розглянути додаткові умови на клас функцій $y(\vec{x})$. Будемо шукати залежність $y(\vec{x})$ серед лінійно-параметричних рівнянь у такому загальному вигляді:

$$
y(\vec{x})=\vec{\varphi}^{T}(\vec{x}) \cdot \vec{b},
$$

де $\vec{b}$ - вектор невідомих оцінок параметрів; $\vec{\varphi}^{T}(\vec{x})$ - вектор невідомих базисних функцій, відомого класу (наприклад, поліноміальні функції). Розмірність $m$ цих векторів на початку процедури ідентифікації є заданою.

3 врахуванням вище викладеного та співвідношень (1)-(4), задача структурної ідентифікації моделі "вхід-вихід" на основі інтервальних даних (2) зводиться до знаходження такої множини залежностей (4), які забезпечують умови сумісності інтервальної системи лінійних (відносно параметрів) алгебраїчних рівнянь (ІСЛАР)

$$
\left\{\begin{array}{l}
y_{1}^{-} \leq b_{1} \varphi_{1}\left(\vec{x}_{1}\right)+\ldots+b_{m} \varphi_{m}\left(\vec{x}_{1}\right) \leq y_{1}^{+} ; \\
\vdots \\
y_{i}^{-} \leq b_{1} \varphi_{1}\left(\vec{x}_{i}\right)+\ldots+b_{m} \varphi_{m}\left(\vec{x}_{i}\right) \leq y_{i}^{+} ; \\
\vdots \\
y_{N}^{-} \leq b_{1} \varphi_{1}\left(\vec{x}_{N}\right)+\ldots+b_{m} \varphi_{m}\left(\vec{x}_{N}\right) \leq y_{N}^{+} ;
\end{array}\right.
$$


Зауважимо, що розв'язком ІСЛАР (5) є множина $\Omega$ оцінок параметрів моделі (4), яка в просторі параметрів - опуклий многогранник. Кожна оцінка 3 множини $\Omega$ при заданій структурі моделі дозволяє отримати одну інтервальну модель, що належить функціональному коридору [3]

$$
[y(x)]=\left[y^{-}(x) ; y^{+}(x)\right]
$$

$$
\begin{gathered}
y^{-}(\vec{x})=\min _{\vec{b} \in \Omega}\left(\vec{\varphi}^{T}(\vec{x}) \cdot \vec{b}\right) \\
y^{+}(\vec{x})=\max _{\vec{b} \in \Omega}\left(\vec{\varphi}^{T}(\vec{x}) \cdot \vec{b}\right)-\text { нижня та верхня межі }
\end{gathered}
$$

функціонального коридору.

Очевидно, що умови сумісності системи (5) можна забезпечити шляхом ускладнення структури початкової моделі $y(\vec{x})=\vec{\varphi}^{T}(\vec{x}) \cdot \vec{b}$ (збільшення кількості параметрів, входів, а для поліноміальної моделі - ступеня полінома).

Загальні підходи до задач структурної ідентифікації інтервальних моделей розглянуті в працях [1, 7]. Зокрема, відмічено, що при розв'язуванні цих задач, важливим питанням $€$ вибір критеріїв оптимальності структури. Розглянемо це питання детальніше. 3 цією метою повернемося до системи нерівностей (5) i вважатимемо, що функція $y(\vec{x})$, яка задає структуру моделі, шукається у класі поліномів. Відомо, що на скінченому наборі вузлів $\vec{x}_{i}(i=1, \ldots, N)$, нарощуючи степінь полінома, завжди можна знайти таку поліноміальну модель, яка задовольняє заданим інтервальним даним.

Нехай знайдена поліноміальна модель $y(\vec{x}, \vec{b})$ залежить від $n$ змінних $x_{1}, \ldots, x_{n}$, степені $p$ і включає $m$ параметрів $b_{1}, \ldots, b_{m}$. Однак вона може виявитися надто складною для аналізу i прогнозування. Внаслідок цього виникає необхідність знаходження поліноміальної моделі максимально простої структури. У випадку наявності групи моделей із структурою однакової складності, перевагу надаватимемо тій моделі, яка забезпечує найменшу похибку прогнозування $\Delta_{y}(\vec{x})$, що задається шириною коридору (6). Загальні характеристики точності інтервальної моделі на області експерименту задаються значеннями середньої та максимальної похибок.

Залежно від особливостей використання моделі, в поняття “простоти” (складності) структури моделі може вкладатися різний зміст. Найбільш типовими ситуаціями у даному випадку є виконання однієї із таких вимог: мінімізація степені полінома $p \rightarrow \min$; мінімізація кількості вхідних змінних моделі $n \rightarrow \min$; мінімізація кількості параметрів поліноміальної моделі $m \rightarrow \min$, за умови забезпечення сумісності інтервальної системи лінійних алгебраїчних рівнянь (5)

Отже, для задач синтезу оптимальної структури, залежно від призначення та особливостей застосування інтервальної моделі статичної системи, заданої поліномом, необхідно використовувати одну чи декілька пар критеріїв: мінімізації степені полінома i похибки прогнозування; мінімізації кількості вхідних змінних моделі i похибки прогнозування; мінімізації кількості параметрів поліноміальної моделі i похибки прогнозування. При цьому необхідним є забезпечення сумісності системи (5).

У випадку поетапного зважування структур інтервальних моделей по критеріях вибраної пари, очевидно, пріоритетними будуть критерії, що мінімізують складність структури, оскільки критерій мінімуму похибки прогнозування інтервальної моделі вимагає значних обчислювальних витрат і на першому етапі, пов'язаному 3 оцінюванням великої кількості претендентів, його застосування $є$ недоцільним. Для наближеної оцінки похибки прогнозування інтервальної моделі в задачах структурної ідентифікації використовують розміри локалізації множини параметрів $\Omega$. Найбільш придатною в даному випадку $\epsilon$ інтервальна локалізація множини розв'язків $\Omega$, тобто описаним $m$ - вимірним прямокутним паралелепіпедом $\Pi^{+}$[4]. У багатовимірному випадку прямокутний паралелепіпед $\Pi^{+}$можна задати через межі окремих параметрів $b_{k}$, тобто інтервальним вектором $[\vec{b}] 3$ елементами $\left[b_{k}{ }^{-} ; b_{k}^{+}\right]$

$$
\Pi^{+}=\left\{\vec{b} \mid b_{k}^{-} \leq b_{k} \leq b_{k}^{+}, k=1, \ldots, m\right\},
$$

$$
\text { де } b_{k}^{-}=\min _{\vec{b} \in \Omega} b_{k}, b_{k}^{+}=\max _{\vec{b} \in \Omega} b_{k} \text {. }
$$

У цьому випадку наближеною оцінкою точності інтервальних моделей може бути об’єм локалізаційного паралелепіпеда

$$
V\left(\Pi^{+}\right)=\prod_{k=1}^{m}\left(b_{k}^{+}-b_{k}^{-}\right) .
$$


Отже в загальному випадку задача структурної ідентифікації інтервальних моделей “вхід-вихід” об'єктів за умов оптимізації складності та точності матиме такий вигляд:

$$
n \rightarrow \min , m \rightarrow \min , V\left(\Pi^{+}\right) \rightarrow \min ,
$$

за умови сумісності системи (5).

\section{ОСОБЛИВОСТІ МЕТОДУ УРАХУВАННЯ ДОДАТКОВИХ АРГУМЕНТІВ}

Розглянемо властивості змішаної інтервальної похибки (3).

Наявність у змішаній моделі невизначеної неусувної похибки $e_{1 i}$ призводить до того, що повторні досліди дозволяють зменшити лише випадкову складову похибки $e_{2 i}$. При повторенні дослідів, істинне значення $y_{0 i}$ належить перерізу випадкових вибіркових інтервалів

$$
d_{i j}=\left[y_{i j}-\Delta_{i} ; y_{i j}+\Delta_{i}\right], \mathrm{j}=1, \ldots, N_{i}, \sum_{i=1} N_{i}=N
$$

Якщо ж вказана умова не виконується, тобто $\bigcap_{j=1}^{N_{i}} d_{i j}=\varnothing$, то для забезпечення сумісності системи (5) необхідно збільшувати $\Delta_{i}$.

$$
\text { Нехай } \bigcap_{j=1}^{N_{i}} d_{i j} \neq \varnothing . \quad \text { Позначимо }
$$
результуючу ширину (перерізу) інтервалу $S_{N_{i}}$ у $i$-тій точці спостережень за $\Delta_{N_{i}}=s_{N_{i}}^{+}-s_{N_{i}}^{-}$. За відомостями [7], справедливим є вираз

$$
\lim _{N_{i} \rightarrow \infty} M\left(\Delta_{N_{i}}\right)=2 \cdot \Delta_{1 i}
$$

де $M\left(\Delta_{N_{i}}\right)$ - математичне сподівання ширини інтервалу у $i$-тій точці.

Отже при довільному об'ємі вибірки $N_{i}$ за умови $\bigcap_{j=1}^{N_{i}} d_{i j} \neq \varnothing$, перерізом інтервалів у змішаній моделі $\epsilon$ скінчений інтервал 3 шириною, не меншою від $2 \cdot \Delta_{1 i}$, який хоча $\mathrm{i}$ включає істинне значення $y_{0 i}$, але не вироджується в точку.

При застосуванні змішаної інтервальної похибки слушним є таке запитання: за рахунок чого виникає випадкова складова похибки, яка може компенсуватися повторними спостереженнями при одних і тих же значеннях фіксованих вхідних змінних? Очевидно, що випадкова адитивна складова похибки $e_{2 i}$ у формулі (3) переважно зумовлена дією неврахованих i неконтрольованих факторів. Аналіз цієї складової при повторних спостереженнях дозволяе стверджувати, що зростання ii амплітуди, пов'язане iз неврахуванням важливих факторів впливу на “вихід”, призведе до одного із двох випадків: певної компенсації (звуження) ширини $\Delta_{N_{i}}$ результуючого інтервалу $S_{N i}$ - за умови достатньо великого початково заданого значення інтервальної похибки $\Delta_{i}$, чи до необхідності розширення вихідного інтервалу $d_{i j}$ (збільшення $\Delta_{i}$ ), - якщо $\bigcap_{j=1}^{N_{i}} d_{i j}=\varnothing . \mathrm{y}$ будь-якому випадку результуючі інтервали $S_{N i}$ будуть достатньо широкими, що призведе до низької точності інтервальних моделей.

Викладені вище міркування дозволяють підійти до задачі структурної ідентифікації 3 іншої точки зору, а саме критерій складності $n \rightarrow \min$, який задає оптимальну кількість вхідних змінних замінити на критерій “додаткових аргументів-входів”, який задаватиме усереднене на області експерименту співвідношення між шириною результуючого та початкового інтервалів невизначеності

$$
\frac{1}{N} \sum_{i=1}^{N} \frac{\Delta_{N i}}{\Delta_{i}} \stackrel{n, \Delta_{i}}{\longrightarrow} \max
$$

за умови $\bigcap_{j=1}^{N_{i}} d_{i j} \neq \varnothing \quad \forall i$.

Максимальне значення виразу $\frac{1}{N} \sum_{i=1}^{N} \frac{\Delta_{N i}}{\Delta_{i}}$ дорівнює 1 , коли початкова ширина інтервалу залишається незмінною при повторних спостереженнях. У цьому випадку відсутні фактори, які вносять випадкову складову, що дозволяє зменшити ширину інтервалу $\left[y_{i}^{-} ; y_{i}^{+}\right]$ 
шляхом вилучення випадкової складової $e_{2 i}$ i тим самим підвищити точність моделі системи. Заміною критерію $n \rightarrow \min \quad$ в задачі структурної ідентифікації (7), (5) на критерій (9) приходимо до їі такого вигляду:

$$
\begin{aligned}
& \frac{1}{N} \sum_{i=1}^{N} \frac{\Delta_{N i}}{\Delta_{i}} \stackrel{n, \Delta_{i}}{\longrightarrow} \max , m \rightarrow \min \\
& V\left(\Pi^{+}\right) \rightarrow \min ,
\end{aligned}
$$

за умови сумісності системи (5).

Оскільки між виразом $\frac{1}{N} \sum_{i=1}^{N} \frac{\Delta_{N i}}{\Delta_{i}}$ та змінною $n$ в загальному випадку не існує залежності заданої аналітично, то задача структурної ідентифікації (10), ускладнюється, однак їі розв'язки (оптимальні структури моделі) відповідатимуть більшій адекватності. Крім цього, критерій (9) та критерій складності $m \rightarrow \min \epsilon$ протилежними, що дозволить знаходити розумний компроміс між адекватністю, точністю та складністю інтервальної моделі системи.

Алгоритми розв'язування багатокритеріальної задачі (10), за умов (5), як і практичної більшості задач структурної ідентифікації, відносяться до еволютивних алгоритмів. Основою для їх побудови є методи послідовного включення чи виключення елементів структури моделі.

Розглянемо один iз можливих алгоритмів структурної ідентифікації інтервальних моделей системи на основі критеріїв (10) $з$ обмеженнями (5), побудований на методі послідовного включення елементів.

Крок 1. Обчислення діапазону значень $\left[-\Delta_{i} ; \Delta_{i}\right]$ інтервальної похибки. Для обчислення цього діапазону необхідно встановити діапазон значень $\left[-\Delta_{1 i} ; \Delta_{1 i}\right]$ невипадкової обмеженої складової $e_{1 i}$ (метрологічної похибки) та допустиму частку випадкової похибки $e_{2 i}$ у загальній інтервальній похибці. Перехід на крок 2.

Крок 2. Формування базових простих структур моделі (переважно виходячи із фізичних міркувань). Перехід на крок 3.

Крок 3. Селекція структур за умовою $\bigcap_{j=1}^{N_{i}} d_{i j} \neq \varnothing \quad \forall i$. Якщо результатом селекції $\epsilon$ пуста множина, то перехід на крок 4, в протилежному випадку - на крок 5 .

Крок 4. Генерування нових структур шляхом доповнення елементами типу $b_{k} \cdot x_{k} 3$ новими факторами. Перехід на крок 3.

Реалізація цього кроку одночасно вимагає модифікації існуючого масиву експериментальних даних (матриці $X$ та інтервального вектора $\lfloor\vec{Y}\rfloor)$. Вказана модифікація проводиться шляхом повторного проведення експериментів у фіксованих точках із врахуванням додаткових факторів впливу $x_{k}$. Ї̈і метою є забезпечення умови $\bigcap_{j=1}^{N_{i}} d_{i j} \neq \varnothing \forall i$ хоча б для одної згенерованої структури.

Крок 5. Селекція структур за критерієм (9). Перехід на крок 6.

Крок 6. Селекція структур за умовою сумісності інтервальних систем лінійних алгебраїчних рівнянь (5), побудованих для отриманих структур. Якщо результатом селекції є пуста множина, то перехід на крок 7, в протилежному випадку - на крок 8 .

Крок 7. Генерування нових структур моделей, шляхом доповнення новими елементами. Як правило при нарощуванні структури додаються однотипні елементи. Наприклад, якщо вихідною структурою була лінійна за факторами-входами $y(\vec{x})=\vec{x}^{T} \cdot \vec{b} \quad$ структура, то нарощування проводиться елементами, які включають взаємодіі факторів: $b_{k r} \cdot x_{k} \cdot x_{r}$. Таке нарощування призводить до появи множини рівнозначних за критерієм складності структур моделей. Перехід на крок 6.

Крок 8. Селекція структури за критерієм точності $V\left(\Pi^{+}\right) \rightarrow \min . \quad$ Закінчення процедури структурної ідентифікації.

У наведеному алгоритмі найбільш трудомістким $є$ крок 4, оскільки вимагає процедури модифікації існуючого масиву даних, переважно шляхом проведення повторних спостережень без урахування попередніх результатів.

\section{АНАЛІЗ МОЖЛИВОСТЕЙ МЕТОДУ УРАХУВАННЯ ДОДАТКОВИХ АРГУМЕНТІВ}

Розглянемо можливості запропонованого алгоритму при забезпеченні однозначності розв'язку на прикладі задачі структурної ідентифікації моделі характеристики кола 
високовольтного комутатора, яке широко використовуються в розподілених системах захисту і управління енергосистем. На рисунку 1 наведені графіки для гармонічної компоненти струму перехідного процесу в момент розімкнення контактів високовольтного комутатора.

На рисунку використані такі позначення: $f$ середньоквадратична величина періодичної компоненти струму перехідного процесу віднесена до величини струму в момент $t=0$ (початкова величина струму відома для всіх типів елементів енергосистеми); $x_{1}$ - проміжок часу після розмикання контактів; $x_{2}-$ відносна величина, яка характеризує віддаленість елементу енергосистеми від точки короткого замикання.

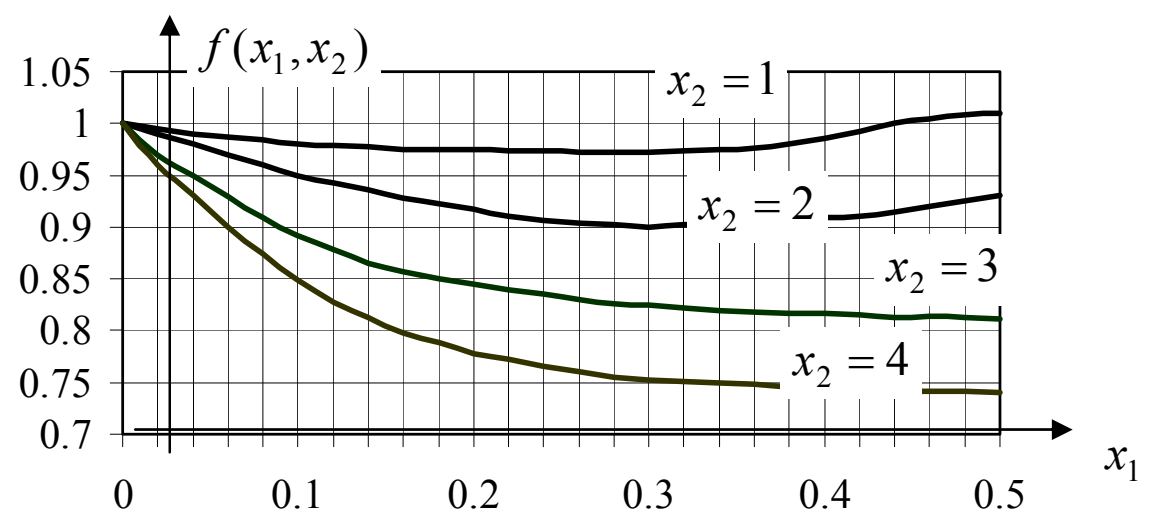

Рис. 1. Графіки функцій струму перехідного процесу.

Як видно з рис. 1 струм перехідного процесу залежить від двох аргументів-факторів: часова змінна перехідного процесу та віддаленості комутованої апаратури від точки короткого замикання.

Застосування графіка дозволяє побудувати таблицю вихідних даних для ідентифікації структури (таблиця 1).

Таблиця 1.

\begin{tabular}{|c|c|c|c|c|c|c|}
\hline$i$ & $x_{1 i}(\mathrm{c})$ & $x_{2 i}$ & $\Delta_{1 i}$ & $\Delta_{2 i}$ & $y_{i}^{-}$ & $y_{i}^{+}$ \\
\hline 1 & 0,1 & 1 & 0,0197 & 0,00985 & 0,9555 & 1,0146 \\
2 & 0,2 & 1 & 0,0195 & 0,00975 & 0,9458 & 1,0043 \\
3 & 0,4 & 1 & 0,0197 & 0,00985 & 0,9555 & 1,0146 \\
4 & 0,5 & 1 & 0,0202 & 0,0101 & 0,9797 & 1,0403 \\
5 & 0,1 & 2 & 0,019 & 0,0095 & 0,9215 & 0,9785 \\
6 & 0,2 & 2 & 0,0184 & 0,0092 & 0,8924 & 0,9476 \\
7 & 0,3 & 2 & 0,018 & 0,009 & 0,873 & 0,927 \\
8 & 0,4 & 2 & 0,0182 & 0,0091 & 0,8827 & 0,9373 \\
9 & 0,5 & 2 & 0,0184 & 0,0092 & 0,8924 & 0,9476 \\
10 & 0,1 & 3 & 0,0178 & 0,0089 & 0,8633 & 0,9167 \\
11 & 0,3 & 3 & 0,0166 & 0,0083 & 0,8051 & 0,8549 \\
12 & 0,5 & 3 & 0,0162 & 0,0081 & 0,7857 & 0,8343 \\
13 & 0,1 & 4 & 0,017 & 0,0085 & 0,8245 & 0,8755 \\
14 & 0,3 & 4 & 0,0152 & 0,0076 & 0,7372 & 0,7828 \\
15 & 0,5 & 4 & 0,0148 & 0,0074 & 0,7178 & 0,7622 \\
\hline
\end{tabular}

Для структурної ідентифікації моделі, яка описує залежність струму розглянемо три варіанти вихідної структури:

- $\quad$ квадратична структура 3 фактором $x_{1}$ за припущення, що фактор $x_{2}$ є несуттєвим: $y(x)=b_{0}+b_{1} \cdot x_{1}+b_{2} \cdot x_{1}^{2}$;
- $\quad$ квадратична структура 3 фактором $x_{2}$ за припущення, що фактор $x_{1} \epsilon$ несуттєвим: $y(x)=b_{0}+b_{1} \cdot x_{2}+b_{2} \cdot x_{2}^{2}$

- лінійна структура 3 врахуванням обох факторів $x_{1}$ та $x_{2}$ : 
$y(x)=b_{0}+b_{1} \cdot x_{1}+b_{2} \cdot x_{2}+b_{3} \cdot x_{1} \cdot x_{2}$ даних, на основі наведених графіків, задамо

Для реалізації алгоритму використаємо розроблений для цих цілей модуль SYNSTRUC 2.0, екранні форми програмного інтерфейсу, якого наведенні на рис. 2.

Реалізацію алгоритму проведемо в два етапи. $\Delta_{2 i}$ задамо $50 \%$ від обмеженої похибки $\Delta_{1 i}$.

Отже, задана інтервальна похибка спостережень $\Delta_{i}$ для усіх варіантів дорівнює $\pm 3 \%$.

На першому етапі (крок 1) алгоритму для усіх варіантів похибку представлення табличних

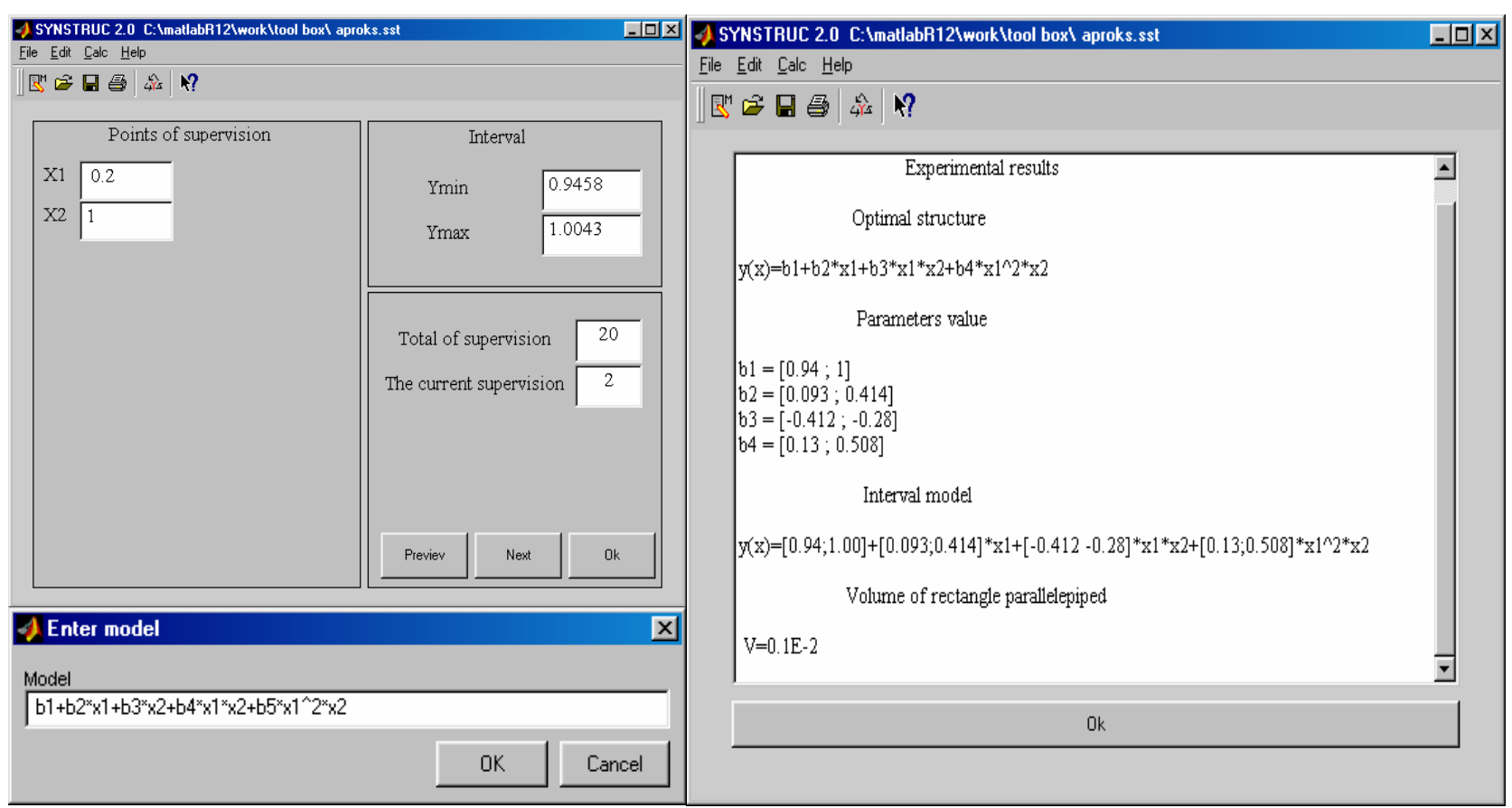

Рис. 2. Екранні форми модуля SYNSTRUC 2.0.

\section{Варіант 1.}

Крок 2. Формуємо початкову структуру $y(x)=b_{0}+b_{1} \cdot x_{1}+b_{2} \cdot x_{1}^{2}$. Перехід на крок 3 .

Крок 3. Перерізом отриманих вибіркових інтервалів при $x_{11}=x_{15}=x_{110}=x_{113}=0,1 є$ пуста множина

$$
\{[0,955 ; 1,0146] \cap[0,9215 ; 0,9785] \cap[0,8633 ; 0,9167] \cap[0,8245 ; 0,8755]\}=\varnothing .
$$

Перехід на крок 4.

Крок 4. Враховуємо інші фактори. В нашому випадку, фактор $x_{2}$. Отримані структури:

$$
\begin{aligned}
y(x)= & b_{0}+b_{1} \cdot x_{1}+b_{2} \cdot x_{2}+b_{3} \cdot x_{1}^{2} \\
& y(x)=b_{0}+b_{1} \cdot x_{1}+b_{2} \cdot x_{2}+b_{3} \cdot x_{1}^{2}+b_{4} \cdot x_{2}^{2}
\end{aligned}
$$

Перехід на крок 3.

Крок 3. Перерізом вибіркових інтервалів, при повторені спостережень за даних умов,

$$
\begin{aligned}
& {[0,955 ; 1,0146] \cap[0,9458 ; 1,0043] \cap[0.955 ; 1.0146] \cap[0,9797 ; 0,0403] \cap} \\
& {[0,955 ; 1,0146] \cap[0,9215 ; 0,9785] \cap[0,8633 ; 0,9167] \cap[0,8245 ; 0,8755]}
\end{aligned}
$$

$€$ пуста множина. Оскільки враховані всі аргументи, переходимо на крок 6.
Крок 6. На шостому кроці алгоритму отримуємо пусту множину для згенерованих 
структур. Перехід на крок 7.

Крок 7. Генеруємо структури доповненням нових елементів типу $b_{i} \cdot x_{1} \cdot x_{2}$ та $b_{i} \cdot x_{1}^{2} \cdot x_{2}$.

1 .

$y(x)=b_{0}+b_{1} \cdot x_{1}+b_{2} \cdot x_{1}^{2}+b_{3} \cdot x_{1} \cdot x_{2}$ 2.-

$y(x)=b_{0}+b_{1} \cdot x_{1}+b_{2} \cdot x_{1} \cdot x_{2}+b_{3} \cdot x_{1} \cdot x_{2}^{2}$

3.

$y(x)=b_{0}+b_{1} \cdot x_{1}+b_{2} \cdot x_{1} \cdot x_{2}+b_{3} \cdot x_{1}^{2} \cdot x_{2}$

4.

Крок 6. Виконання умови сумісності системи (5) забезпечила п'ята структура із незначущим параметром $b_{2}$ :

$$
\begin{gathered}
y(x)=[0,94 ; 1,00]+[0.093 ; 0.414] \cdot x_{1}+[-0.0589 ; 0.0133] \cdot x_{2}+ \\
+[-0,412 ;-0,280] \cdot x_{1} \cdot x_{2}+[0,130 ; 0,508] \cdot x_{1}^{2} \cdot x_{2}
\end{gathered}
$$

Перехід на крок 8.

Крок 8. $V\left(\Pi^{+}\right)=0,1 \cdot 10^{-2}$. Кінець процедури.

Отже, отримали наступну структуру для першого варіанту:

Bаріант2.

$$
y(x)=b_{0}+b_{1} \cdot x_{1}+b_{2} \cdot x_{1} \cdot x_{2}+b_{3} \cdot x_{1}^{2} \cdot x_{2}
$$

Крок 2. Формуємо початкову структуру $y(x)=b_{0}+b_{1} \cdot x_{2}+b_{2} \cdot x_{2}^{2}$. Перехід на крок 3 .

Крок 3. На третьому кроці умова $\bigcap_{j=1}^{N_{i}} d_{i j} \neq \varnothing \quad$ виконується при $x_{21}=x_{22}=x_{213}=x_{214}=1$.

$$
[0,955 ; 1,0146] \cap[0,9458 ; 1,0043] \cap[0.955 ; 1.0146] \cap[0,9797 ; 0,0403]=[0,9797 ; 1,0043] \text {. }
$$

Перехід на крок. 5.

Крок 5. Обчислюємо значення критерію “додаткового урахування аргументів” для даної структури $\frac{1}{4} \sum_{i=1}^{4} \frac{\Delta_{i}}{\Delta_{1}}=0,996$. Перехід на крок 6 .
Крок 6. Дана структура не задовольняє умові сумісності системи (4.5). Перехід на крок 7.

Крок 7. Включаємо додаткові елементи, отримаємо наступні структури:

$$
\begin{aligned}
& \text { 1.- } y(x)=b_{0}+b_{1} \cdot x_{1}+b_{2} \cdot x_{2}+b_{3} \cdot x_{1} \cdot x_{2} \\
& \text { 2. }-y(x)=b_{0}+b_{1} \cdot x_{1}+b_{2} \cdot x_{1}^{2}+b_{3} \cdot x_{2}+b_{4} \cdot x_{2}^{2}+b_{5} \cdot x_{1} \cdot x_{2} \\
& \text { 3. } y(x)=b_{0}+b_{1} \cdot x_{1}+b_{2} \cdot x_{1}^{2}+b_{3} \cdot x_{2}+b_{4} \cdot x_{1} \cdot x_{2} \\
& \text { 4. - } y(x)=b_{0}+b_{1} \cdot x_{1}+b_{2} \cdot x_{2}+b_{3} \cdot x_{2}^{2}+b_{4} \cdot x_{1} \cdot x_{2} \\
& \text { 5. - } y(x)=b_{0}+b_{1} \cdot x_{1}+b_{2} \cdot x_{2}+b_{3} \cdot x_{1} \cdot x_{2}+b_{4} \cdot x_{1}^{2} \cdot x_{2} . \\
& \text { 6. - } y(x)=b_{0}+b_{1} \cdot x_{1}+b_{2} \cdot x_{2}+b_{3} \cdot x_{1} \cdot x_{2}+b_{4} \cdot x_{1} \cdot x_{2}^{2}
\end{aligned}
$$

Перехід на крок 6 .

Крок 6. Серед згенерованих структур сумісність системи забезпечила тільки п'ята структура: 


$$
y(x)=[0,94 ; 1,00]+[0.093 ; 0.414] \cdot x_{1}+[-0,412 ;-0,280] \cdot x_{1} \cdot x_{2}+[0,130 ; 0,508] \cdot x_{1}^{2} \cdot x_{2}
$$

Перехід на крок 8.

Крок 8. $V\left(\Pi^{+}\right)=0,1 \cdot 10^{-2} . \quad$ Кінець процедури.

Отже, структура моделі для другого варіанту:

$$
y(x)=b_{0}+b_{1} \cdot x_{1}+b_{2} \cdot x_{1} \cdot x_{2}+b_{3} \cdot x_{1}^{2} \cdot x_{2}
$$

\section{Варіант 3.}

Крок 2. Початкова структура враховує обидва аргументи:

$$
y(x)=b_{0}+b_{1} \cdot x_{1}+b_{2} \cdot x_{2}+b_{3} \cdot x_{1} \cdot x_{2} .
$$

Оскільки в цьому випадку враховуються всі фактори впливу, відразу переходимо на шостий крок алгоритму.

Крок 6. Отримавши несумісну систему рівнянь (5), перехід на крок 7.

Крок 7. Нарощуємо структуру елементами виду $b_{k} \cdot x_{i}^{2} \cdot x_{j}, i \neq j$. Згенеровані структури:

$$
\begin{array}{r}
y(x)=b_{0}+b_{1} \cdot x_{1}+b_{2} \cdot x_{2}+b_{3} \cdot x_{1} \cdot x_{2}+b_{4} \cdot x_{1} \cdot x_{2}^{2}, \\
y(x)=b_{0}+b_{1} \cdot x_{1}+b_{2} \cdot x_{2}+b_{3} \cdot x_{1} \cdot x_{2}+b_{4} \cdot x_{1}^{2} \cdot x_{2}
\end{array}
$$

Крок 6. Для другої структури виконується умова сумісності, але другий параметр виявився незначущим. Відповідно отримуємо розв'язок:

$$
y(x)=b_{0}+b_{1} \cdot x_{1}+b_{2} \cdot x_{1} \cdot x_{2}+b_{3} \cdot x_{1}^{2} \cdot x_{2}
$$

Як бачимо у всіх варіантах прийшли до однієї структури моделі.

Тепер на другому етапі аналогічні варіанти розглянемо для частки випадкової обмеженої похибки, вибраної у такий спосіб, щоб для усіх варіантів на кроці 3 виконувалася умова $\bigcap_{j=1}^{N_{i}} d_{i j} \neq \varnothing \quad \forall i$.

Її виконання гарантовано забезпечується при $300 \%$ частки випадкової похибки $\Delta_{2 i}$ від метрологічної похибки сенсорів $\Delta_{1 i}$, тобто при інтервальній похибці спостережень $\Delta_{i}$, яка дорівнює $\pm 8 \%$. В результаті реалізації алгоритму для усіх трьох вище зазначених варіантів отримали структуру у такому вигляді:

Перехід на крок 6.

$$
y(x)=[0,86 ; 0,977]+[0,062 ; 0.733] \cdot x_{1}+[-0,273 ;-0,107] \cdot x_{1} \cdot x_{2}, \quad \text { при } \quad \text { об‘ } є і
$$
локалізаційного паралелепіпеда - $V\left(\Pi^{+}\right)=0,13 \cdot 10^{-1}$.

Як видно, структура отримана на другому етапі, коли інтервальна похибка зросла від 3\% до $8 \%$, відрізняється від структури першого етапу.

Таким чином, розв'язки (отримані структури моделей) при реалізації розглянутого алгоритму залежать від інтервалу невизначеності для вихідної змінної, який неможливо визначити тільки за наявності похибок сенсорів. При задані широких інтервалів невизначеності вихідної змінної отримуємо моделі 3 незадовільними прогностичними властивостями. Для зменшення чутливості розглянутого алгоритму структурної ідентифікації до початково заданих інтервальних похибок необхідна його модифікація у напрямку адаптивного регулювання допустимої частки випадкової похибки по відношенню до похибки вимірювання, застосуванням ітераційної процедури у такому вигляді:

$$
\left[-\Delta_{i} ; \Delta_{i}\right]=\left[-\Delta_{1 i} ; \Delta_{1 i}\right] \cdot\left(1+k^{*} \delta\right)
$$

де $k$ - номер ітерації, $\delta$ - частка випадкової похибки від похибки вимірювання.

У формулі (11) частка випадкової похибки в загальній інтервальній похибці для вихідної змінної в процесі реалізації ітераційної процедури зростає лінійно. Очевидно, що підбираючи закон зміни частки випадкової складової похибки можна забезпечувати різну обчислювальну складність отримання адекватних моделей статичних систем.

Вище зроблені зауваження, дозволяють модифікувати вище розглянутий алгоритм у такий спосіб.

Крок 1. Розрахунок діапазону значень $\left[-\Delta_{i} ; \Delta_{i}\right]$ інтервальної похибки за формулою:

$$
\left[-\Delta_{i} ; \Delta_{i}\right]=\left[-\Delta_{1 i} ; \Delta_{1 i}\right] \cdot\left(1+k^{*} \delta\right)
$$

Перехід на крок 2.

Крок 2. Формування базових простих структур моделі (виходячи із фізичних міркувань). Перехід на крок 3. 
Крок 3. Селекція структур за умовою $\bigcap_{j=1}^{N_{i}} d_{i j} \neq \varnothing \quad \forall i$. Якщо результатом селекції $\epsilon$ пуста множина, то перехід на крок 4, в протилежному випадку - на крок 5 .

Крок 4. Генерування нових структур шляхом доповнення елементами типу $b_{k} \cdot x_{k} 3$ новими факторами. Перехід на крок 3 .

Крок 5. Селекція структур за критерієм (9). Перехід на крок 6.

Крок 6. Селекція структур за умовою сумісності інтервальних систем лінійних алгебраїчних рівнянь (5), побудованих для отриманих структур. Якщо результатом селекції $\epsilon$ пуста множина, то перехід на крок 7, в протилежному випадку - на крок 8 .

Крок 7. Генерування нових структур моделей, шляхом доповнення новими елементами, які включають взаємодії факторів: $b_{k r} \cdot x_{k} \cdot x_{r}$. Перехід на крок 6.

Крок 8. Селекція структури за критерієм точності $V\left(\Pi^{+}\right) \rightarrow \min$.

Крок 9. Аналіз структури за критерієм складності. Якщо структура занадто складна, то $k=k+1$ та перехід на крок 1 , інакше закінчення процедури.

Запропонований алгоритм є більш гнучкий і вирішує проблему визначення інтервалів оцінки виходів системи.

\section{висновок}

\section{Дослідження алгоритму} ідентифікації інтервальних

структурної моделей, побудованого на основі методу урахування додаткових аргументів-входів показало, що при забезпеченні однозначних розв'язків він $\epsilon$ чутливим до ширини початково заданих інтервалів невизначенності для вихідної змінної. Для зменшення цього впливу на результати структурної ідентифікації, запропоновано модифікацію даного алгоритму шляхом введення ітераційної процедури підбору інтервалу оцінки вихідної змінної.

\section{ЛITEPATУРA}

1. Вощинин А.П., Дывак М.П. Планирование оптимального насыщенного эксперимента в задачах построения интервальных моделей // Заводская лаборатория. - 1993. - №1. - C.56 - 59.

2. Журбенко И. Г., Кожевникова И. Н. Стохастическое моделирование процесов - М.: Изд-во МГУ, 1990. - 148 с.
3. Дивак М.П., Франко Ю.П. Оцінювання області параметрів інтервальної моделі на основі блоку насиченого експерименту при аналізі інтервальних даних // Матеріали 5 міжн. конф. “Досвід розробки і застосування САПР в мікроелектроніці”.- Львів. 1999. С.188-189

4. Дивак М.П. Аналіз точності лінійної інтервальної моделі в задачах статичної ідентифікації // Вісн. ДУ “Львівська політехніка”. Автоматика, вимірювання та керування. - 1999.- № 366. - С. 31-35.

5. Ивахненко А.. Г., Мюллер Й.А. Самоорганизация прогнозирующих моделей. К.: Техника, 1985.

6. Степашко В. С. Костенко Ю. В. Исследование свойств комбинаторноселекционного (многоэтапного) алгоритма МГУА // Сб. науч. тр. междунар. науч.-уч. центра информ. Технологий и систем. Моделирование и управление состоянием экологоэкономических систем региона.- Киев, 2001. - C. 96-100.

7. Дивак М. П. Метод структурної ідентифікації моделей "вхід-вихід" статичних систем на основі даних зі змішаною інтервальною похибкою// Відбір і обробка інформації. 2003. Вип. 19 (95) С.68-73.

8. Дывак М. П. Интервальние модели ошибок в прикладных задачах// Материалы конф. "Актуальные проблемы прикладной математики". - Саратов, 1991.- том 1.

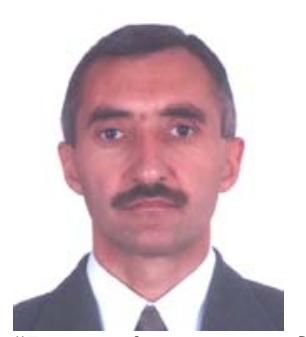

$\begin{array}{ll}\text { Дивак Микола Петрович } \\ \text { народився } 1964 \text { року. В } 1986 \\ \text { році закінчив Львівський } \\ \text { політехнічний інститут i } \\ \text { отримав } & \text { кваліфікацію } \\ \text { радіоінженера. В } 1992 \text { рочі } \\ \text { захистив } & \text { кандидатську } \\ \text { дисертацію на тему }\end{array}$

"Розробка методів оптимального планування експерименту і аналізу інтервальних даних". В 1999 році вступив до докторантури Тернопільської академії народного господарства і у 2003 році захистив дисертацію на здобуття вченого ступеня доктора технічних наук на тему "Теоретичні засади побудови моделей "вхід-вихід" статичних систем методами аналізу інтервальних даних". Опублікував понад 80 наукових праць. На даний час працює завідувачем кафредри комп'ютерних наук інституту комп'ютерних технологій Тернопільської академії народного господарства.

Область наукових інтересів: розробка та застосування методів множинного оцінювання та інтервального аналізу для моделювання 
статичних і динамічних систем в сфрері економіки, екології та технологічних галузях.

\footnotetext{
Володимир Манжула народився у смт. Чемерівці Хмельницької обл. в $1976 p$. У 2000 році закінчие фрізикоматематичний фракультет Кам'янець-Подільського державного педагогічного університету. Працюе $у$ Львівському технічному

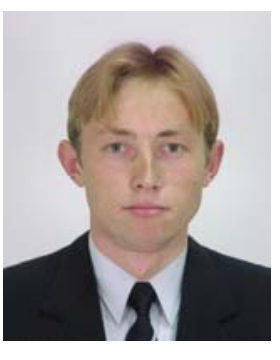
коледжі. Основні наукові інтереси пов'язані із задачами структурної ідентифрікації інтервальних моделей статичних систем. Опублікував 5 наукових праць.
} 